\title{
REVISITANDO O PENSAMENTO DO PROFESSOR CARLOS AUGUSTO MONTEIRO COMO MOTIVAÇÃO ÀS NECESSÁRIAS REFLEXÕES EPISTEMOLÓGICAS DOS ESTUDOS GEOGRÁFICOS DA NATUREZA
}

\section{REVISITING THE TEACHER'S THOUGHT CARLOS AUGUSTO MONTEIRO AS A MOTIVATION TO THE NEEDED EPISTEMOLOGICAL REFLECTIONS OF GEOGRAPHICAL STUDIES OF NATURE}

\author{
Isorlanda Caracristi \\ ${ }^{1}$ Universidade Estadual Vale do Acaraú (UVA), Sobral, CE, Brasil
}

Correspondência para: Isorlanda Caracristi (icaracristi@hotmail.com)

doi: 10.12957/geouerj.2019.40952

Recebido em: 15 ago. 2018 | Aceito em: 19 out. 2018

\section{SCREENED BY $\checkmark$ iThenticate}

\section{RESUMO}

Revisitar Monteiro e dialogar com suas ideias, instigando a reflexão teórica no âmbito da Geografia Física, tendo a epistemologia climatológica como tema norteador, é o objetivo principal deste artigo. O pragmatismo que vem dominando as dissertações e teses no âmbito nacional de pós-graduação em Geografia vem nos dificultando fazer a diferença no contexto nacional das ciências. Ousar é imprescindível aos avanços metodológicos e conceituais. Precisamos, mais que nunca, auscultar o mestre e nos tornarmos verdadeiros "mensageirosportadores" do conhecimento geográfico.

Palavras-chave: epistemologia geográfica. natureza. clima. organização ativa. sistemas complexos.

\begin{abstract}
Revisiting Monteiro and dialoguing with his ideas, instigating theoretical reflection in the field of Physical Geography, with climatological epistemology as the guiding theme, is the main objective of this article. The pragmatism that has dominated the dissertations and theses in the national scope of postgraduate in Geography has made it difficult for us to make the difference in the national context of the sciences. Daring is imperative to methodological and conceptual advances. We need, more than ever, to listen to the master and become true " messengers-conveyers" of geographical knowledge.
\end{abstract}

Keywords: geographical epistemology. nature. climate. active organization. complex systems.

\section{Por que refletir teoricamente em Geografia Física? Breve instigação introdutória.}

A Geografia Física brasileira - pelo uso acrítico dos Sistemas de Informação Geográfica (SIG's) e geoprocessamento de dados como fins e não como meios técnicos de produção de dados e informações, associado à fragmentação excessiva dos estudos de caso, que imperam nas pesquisas dos programas de pós-graduação - vem perdendo, com raras exceções, a sua episteme geográfica.

Como uma espécie de confissão obrigatória à legalização teórica, as pesquisas promulgam-se “com bases sistêmicas" e citam Bertalanffy e sua Teoria Geral dos Sistemas (TGS) ou se referem em suas 
revisões teóricas quase sempre a Sotchava, Bertrand e Tricart. A santa trindade da Geografia Física nacional, que finda afigurando nas referidas revisões como algo que, na verdade, não intermedia e nem funda a produção do conhecimento, visto que o processo de produção e as análises dos resultados apresentam-se, em sua maioria, desconectados dos pressupostos metodológicos e sem dialogar com os fundamentos teóricos.

Quão raras, atualmente, são as teses em Geografia Física que se dedicam a buscas teóricas ou metodológicas! Sem nenhum demérito, as nossas teses estão se transformando em dissertações “melhoradas", sem entrar na discussão do aligeiramento e do produtivismo do sistema de pósgraduação brasileiro, que vêm contribuindo significativamente para o pragmatismo das pesquisas.

Contudo, esse vazio teórico em nossa prática, faz-nos perder nossas bases epistemológicas, nos impossibilitando de fazer a diferença e nos leva a repetição de receitas genéricas, a nos reduzirmos a produtores de diagnósticos físicos. Estamos perdendo o caráter geográfico dos estudos da Natureza.

A Natureza, para nós, está sendo a natureza comum às ciências naturais e exatas. No entanto, a "Física” geográfica não deve ser a da física clássica ou geológica, essencialmente mecanicista e abiótica, e por isso, dicotômica ao ser humano, à sociedade.

A "Física" geográfica é a physis enquanto matriz fundadora de organizações/sistemas espaciais, referenciados na escala histórica de vivência humana e que integra os conceitos de geossistema, paisagem, região, território e lugar. É a physis que não se contrapõe ao Humano, mas que nega o "antropocentrismo", ou seja, uma visão humana não narcisista.

Quem mais, no contexto científico nacional, que o Professor Carlos Augusto de Figueiredo Monteiro se preocupou com as questões teórico-metodológicas e epistemológicas no âmbito dos estudos geográficos da Natureza? Por isso, revisitar seu sempre atual pensamento e dialogar com ele, fazendo contrapontos complementares que possam reavivar a reflexão teórica no âmbito da epistemologia climatológica, é sempre fecundo e se constitui no objetivo maior deste trabalho. 


\section{A organização, a sucessão e o ritmo: a tríade ontológica do clima}

O professor Carlos Augusto Monteiro, ao longo de suas obras no contexto da Climatologia Geográfica, sempre se dedicou à reflexão filosófica e conceitual e ao estabelecimento de critérios e procedimentos que revelassem o caráter dinâmico e complexo dos sistemas climáticos, o que culminou em sua proposição denominada “Análise Rítmica dos Tipos de Tempo" (1969 e 1971). Tal proposição, traz em sua episteme a interação do pensamento sistêmico e complexo, onde o ritmo dos tipos de tempo revela o caráter espaço-temporal dos sistemas climáticos, transpondo-os ao âmbito da natureza geográfica.

A dinâmica e expressão espaço-temporal em que Monteiro imbuiu os sistemas climáticos proporcionaram aos geógrafos físicos dedicados à Climatologia uma base teórico-metodológica à produção de conhecimento em níveis e vieses de análise de grande aplicabilidade tanto na dimensão relacional socioespacial como socioambiental.

Com essas premissas, iniciaremos a revisitação por meio de uma citação de Monteiro (1969), onde “sucessão" e "ritmo" são colocados como conceitos básicos à concepção dinâmica do clima,

\footnotetext{
Por coerência com a noção de "sucessão" de que se reveste o caráter geográfico do clima. Porque só o encadeamento dos estados atmosféricos mostra os "tipos" esquematizados na análise meteorológica precedente, em suas perspectivas reais, revestidas em suas infinitas gradações e facetas. Também, é pela sucessão que se percebem as diferentes combinações dos elementos climáticos entre si e suas relações com os demais elementos do quadro geográfico. É a seqüência que conduz ao ritmo, e o ritmo é a essência da análise dinâmica. (MONTEIRO, 1969, p.13).
}

Como nenhuma dinâmica sistêmica se processa pelos seus elementos isoladamente, pressupõe-se que a existência de um tipo climático se defina pela especificação de uma atividade organizativa, onde a sucessão dos tipos de tempo constitui uma síntese progressiva e o ritmo climático a recursão contínua dessa síntese - fazendo da sucessão um padrão que se repete diferentemente no tempo, mantendo e evoluindo o sistema climático. Desta forma, podemos concluir que o clima é um padrão de atividades, que sua ontologia é um simultâneo fluxo-influxo-(re)fluxo. Iniciamos aqui, o diálogo e nossas reflexões consequentes. 
A essência ontológica do clima se expressa pelo seu padrão de organização, pela configuração espaçotemporal de relações que preserva e mantém a identidade do tipo climático.

A interação recursiva (retroalimentação não-linear, própria de sistemas complexos) entre a sucessão dos estados atmosféricos e o ritmo dos tipos de tempo induz o padrão de organização climática e 0 torna auto-organizativo (Figura 1). 0 ritmo conecta os processos e a estabilidade climática: o padrão rítmico-recursivo mantém o sistema climático auto-organizado, preserva a sua autonomia operacional e promove suas dependências (interações) ambientais essenciais à retroalimentação sistêmica:

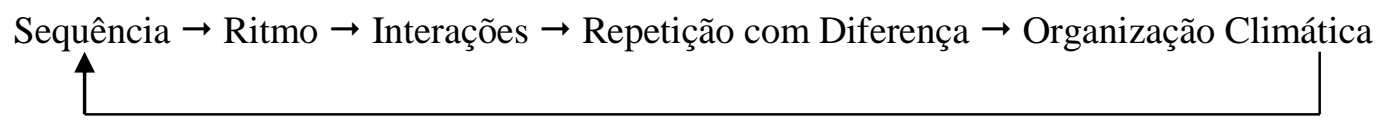

Figura 1. Dinâmica de Auto-Organização Climática(Padrão Auto-Organizativo). Fonte: autora

O fenômeno da auto-organização é uma atividade de regeneração sistêmica, de repetição espaçotemporal de um sistema aberto que se mantém evoluindo e em contínua transformação.

Os sistemas climáticos, como todo sistema natural, são abertos e, por conseguinte, são sistemas estáveis afastados do equilíbrio: pelas trocas de energia e matéria com o meio ambiente (sistemas aninhados em redes holônicas), os processos entrópicos de dissipação de energia são associados aos processos neguentrópicos de retroalimentação, nos remetendo a espiral do tempo, onde há associação antagônica e complementar entre desordem (entropia) e ordem (neguentropia), isto é, entre desorganização e organização, entre degeneração e regeneração sistêmica.

Monteiro (2001) em seu trabalho denominado "De Tempos e Ritmos: Entre o Cronológico e o Meteorológico para a Compreensão Geográfica dos Climas", já se referia ao tempo entrópico climático simbolizado pela "espiral ascendente rítmica" (vide Figura 2).

"Pela figura da espiral ascendente rítmica vislumbra-se a possibilidade de perceber-se que um tal dinamismo assume caráter de um sistema de alta complexidade, uma revelação relativamente recente na ciência e que requer mobilização de novas contribuições como a geometria fractal, energias dissipativas, teoria do caos, dentre outras aquisições”. (MONTEIRO, 2001, p.149) 


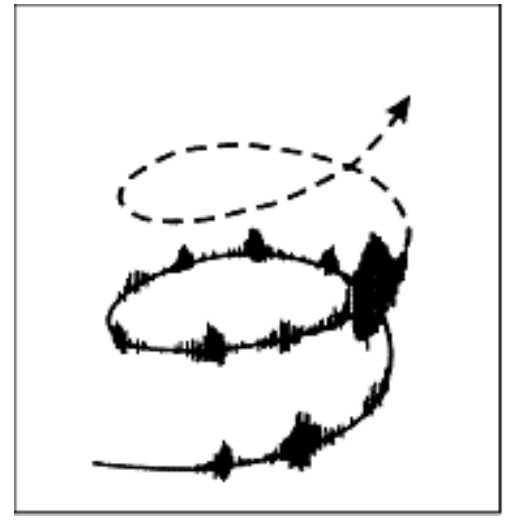

Figura. 2. A Espiral Rítmica (Sistema de Alta Complexidade). Fonte: Monteiro, 2001

A fundamentação científica do fenômeno da auto-organização dos sistemas climáticos passa pelo conceito não clássico de entropia iniciado pelo físico austríaco Ludwig Boltzmann (WYLEN, 1998), que estabeleceu a ligação entre entropia e ordem (entre dissipação de energia e possibilidades organizativas), contrapondo-se à concepção de Clausius (WYLEN, op.cit.) que ao estabelecer a Segunda Lei da Termodinâmica, anunciava uma entropia sempre crescente, levando os sistemas ao equilíbrio térmico (relação excludente entre desordem e ordem), fazendo da entropia um processo linear/unidirecional, com possibilidade organizativa zero, onde tudo era absolutamente previsível.

A concepção de Clausius é da entropia dos sistemas isolados, sem processos de realimentação (seta inexorável e linear do tempo) e a de Boltzmann é a dos sistemas que interagem (tempo espiral das probabilidades).

Com a noção de probabilidade de Boltzmann associada ao conceito de instabilidade de Poincaré (apud PRIGOGINE, 1996) foi destruída a equivalência entre o nível individual (das certezas absolutas) e o nível estatístico (das probabilidades).

A introdução científica da probabilidade, da incerteza, enquanto característica irredutível e intrinsecamente aleatória aos sistemas dinâmicos instáveis, fundamentou matemática e fisicamente o fenômeno da sensibilidade às condições iniciais (SCI), típico de sistema complexos, abertos e instáveis, como os sistemas atmosféricos/climáticos. 
O gráfico clássico cartesiano de marcação exata e dicotômica das variáveis espaciais e temporais (Fig.

3) individuais de um sistema foi substituído por um gráfico de nuvens de pontos (Fig. 4), uma região de probabilidades para predizer a evolução do conjunto e não mais dos comportamentos individuais.

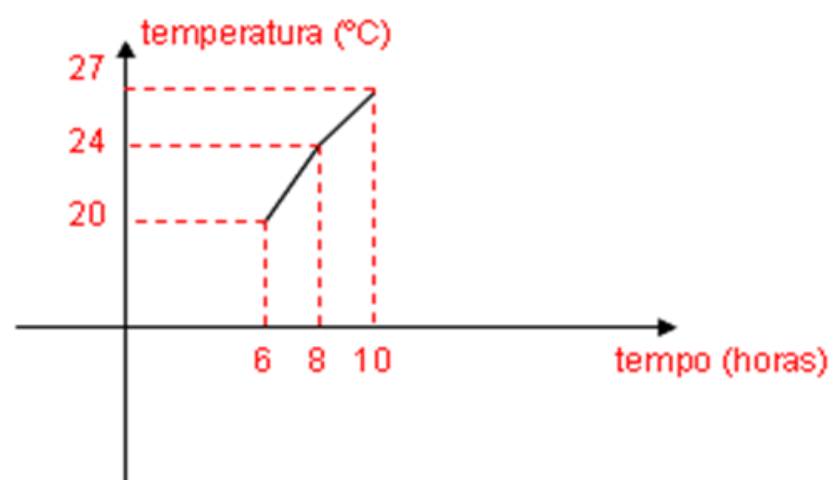

Figura 3. GráficoCartesianoClássico. Fonte:https://educacao.uol.com.br/planos-de-aula/fundamental/matematicaexperiencias-com-grafico-de-linha.htm

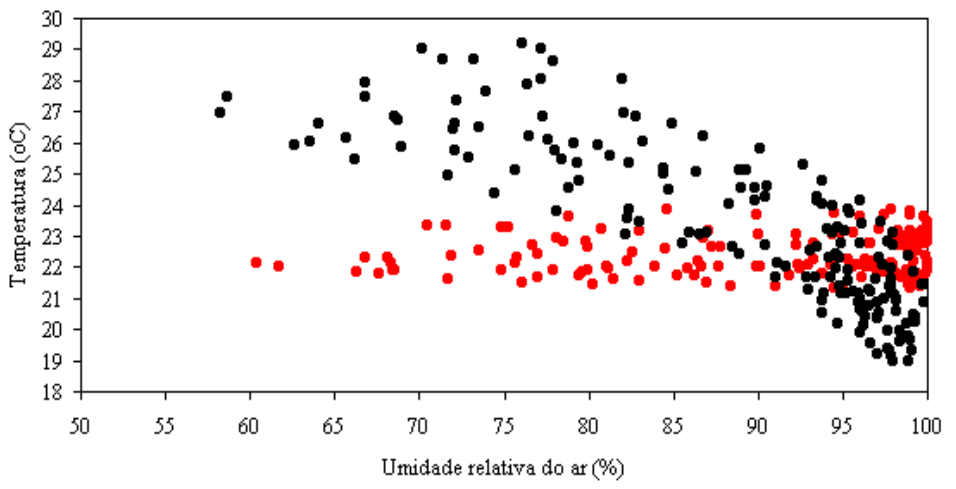

Figura.4 Gráfico de Dispersão (nuvens de pontos)Fonte: ttp://www.cibergeo.org/XSBGFA/eixo3/3.4/043/043.htm

A improbabilidade e a imprevisibilidade adquiriram status científico. A entropia passou a ser a condição básica para a provável estabilidade do sistema, visto que as possibilidades de organização do sistema são proporcionais à dissipação de energia: quanto mais instável ou afastado do equilíbrio maior é a dissipação de energia do sistema, ou seja, maior é a entropia.

Dessa forma, a entropia se insere no contexto do pensamento sistêmico, onde todo sistema se relaciona com seu meio - o contexto dos sistemas abertos, onde existe retroalimentação (relação nãolinear/recursiva) - e assume uma concepção de fenômeno básico do processo de organização dos sistemas naturais. 
Nesse contexto explicativo, o ritmo expressa a dinâmica da estrutura dissipativa do sistema climático, como parafraseia Caracristi (2007), .

\footnotetext{
"Longe do equilíbrio (análise dinâmica), a homogeneidade do tempo (análise separatista) é, com efeito, duplamente destruída: pela estrutura espaço-temporal ativa (tipos de tempo, dinâmica atmosférica), que confere ao sistema o comportamento de uma totalidade organizada (clima), caracterizada por dimensões e um ritmo intrínsecos (ritmo climático), mas também pela história (sucessão dos tipos de tempo, gênese e evolução do sistema) que o aparecimento de tais estruturas implica." (expressões em grifo foram inseridas. Adaptado de PRIGOGINE, 1997, p.122, apud CARACRISTI, 2007, p.26)
}

Em suma, a recursão ou retroalimentação não-linear, própria dos sistemas naturais, que interagem continuamente com o meio, coloca-se como o processo base do círculo organizativo dos padrões sistêmicos e a expressão matemática que legaliza o caráter científico da recursão é a iteração. Como menciona Caracristi (op.cit.)

A iteração é o processo matemático dos laços de realimentação. A iteração é um processo nãolinear, onde uma dada função se repete continuamente sobre si mesma.

Os sistemas não-lineares possuem uma característica peculiar; pequenas alterações podem ter grandes efeitos, pois podem ser amplificados repetidamente por meio de realimentações. Esses processos não-lineares originam uma dinâmica instável e de súbitas emergências de novas formas de organização ou ordem: uma dinâmica de auto-organização. (CARACRISTI, 2007, p. 101)

A tríade climática passa então a consubstanciar-se matematicamente pelo processo iterativo que comprova cientificamente a capacidade espontânea e imprevisível dos sistemas naturais em se organizar e evoluir simultaneamente no tempo e no espaço.

\section{A iteração no contexto da explicação dos padrões organizativos dos sistemas climáticos}

Para nós geógrafos, não é fácil adentrar no mundo das explicações matemáticas, após várias tentativas, encontramos em Capra (2000) um esquema explicativo para a iteração denominado a "Transformação do Padeiro", que elucidou de forma bastante didática a relação entre realimentação/recursão e padrão de organização. 
Segundo Capra (op.cit., p.107), a "Transformação do Padeiro" pode ser explicada ao pegarmos uma função "x", assim apresentada:

$$
\mathrm{f}(\mathrm{x})=\mathrm{x}
$$

- $\quad$ Onde $\mathrm{k}$ pode ser qualquer constante de multiplicação, por exemplo, $\mathrm{f}(3)=3 \mathrm{x}$;

- Cada passo de multiplicação é chamado de "mapeamento";

- Esse tipo de mapeamento é chamado de "mapeamento logístico" ou "equação do crescimento".

Usando o exemplo da função acima, $\mathrm{x}=>3 \mathrm{x}(1-\mathrm{x})$.

A variável "x" pode ser visualizada como um segmento de reta que vai de 0 a 1 , e é fácil calcular os mapeamentos para alguns pontos, como se segue no esquema abaixo (adaptado de CAPRA, 2001, apud CARACRISTI, 2007, p. 102):

$\left.\begin{array}{llll}0 & \rightarrow & 0(1-0) & =0 \\ 0,2 & \rightarrow & 0,6(1-0,2) & =0,48 \\ 0,4 & \rightarrow & 1,2(1-0,4) & =0,72 \\ 0,6 & \rightarrow & 1,8(1-0,6) & =0,72 \\ 0,8 & \rightarrow & 2,4(1-0,8) & =0,48 \\ 1 & \rightarrow & 3(1-1) & =0\end{array}\right\}$

REALIMENTAÇÃO ou recursividade

circular mantém a fronteira da forma, o padrão de organização.
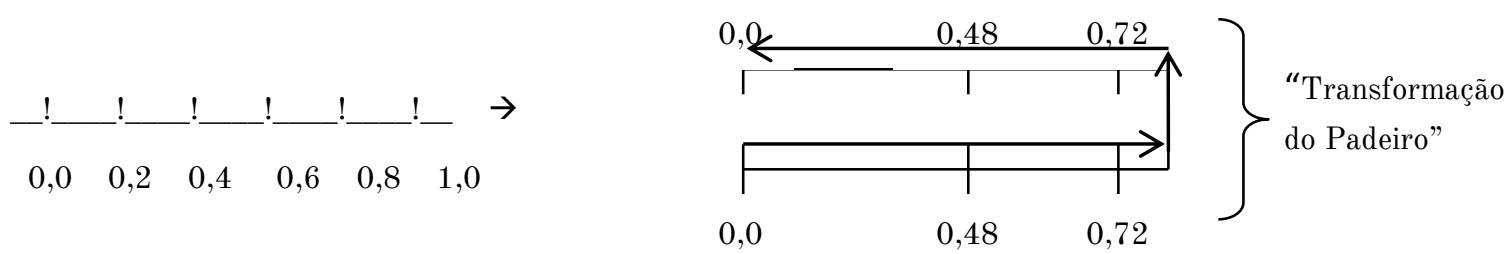

A "Transformação do Padeiro" é a iteração que resulta em repetidas operações de estender e dobrar, onde os mínimos erros de arredondamento irão se acumular e se amplificar, produzindo grande incerteza de previsões: efeito amplificar (quantitativo), que leva a uma transformação (qualitativo) do sistema. 
A iteração proporciona a "Sensibilidade às Condições Iniciais" (SCI) dos eventos, a qual nos referimos anteriormente.

A partir desse esquema explicativo, podemos inferir que o sistema atmosférico/climático é um sistema com alta SCI, ou seja, um sistema com contínuas instabilidades estruturais (sistema afastado do equilíbrio).

A estrutura atmosférica é dissipativa (estrutura estável afastada do equilíbrio) como exemplifica Capra (op.cit) e a sua dinâmica organizativa é composta por um padrão complexo de comportamentos coletivos instáveis associados a comportamentos singulares estáveis interconectantes. E o clima é um desses padrões singulares estáveis interconectantes, uma estrutura espaciotemporal ativa.

“... estruturas dissipativas de grande estabilidade surgem em trovoadas em condições atmosféricas especiais. Furacões e tornados são vórtices de ar em violento movimento giratório ... diferenças de temperatura, expansões e contrações do ar, efeitos da umidade, condensações e evaporações, e assim por diante. As estruturas resultantes são, desse modo, muito mais complexas ... e exibem uma maior variedade de comportamentos dinâmicos ... que podem converter-se em estruturas dissipativas ..." (CAPRA, 2000, p.143)

Então, o paradigma da Organização Ativa defendido por Morin (2003) é validado pela composição matemática da iteração associada aos conceitos de entropia e recursão (retroalimentação não-linear).

\footnotetext{
A idéia do ser não é uma noção substancial. É uma idéia organizacional. Não há ser onde há dispersão, há emergência de ser ali onde há organização. Mas a idéia de ser só toma sua identidade fenomenal onde há organização ativa, ou seja, autonomia e práxis... (MORIN, 2003, p.260)
}

\section{Organização Ativa, um conceito a espera de conversão metodológica em Climatologia}

A previsibilidade determinista não cabe aos sistemas atmosféricos/climáticos que são dinâmicos, instáveis e dissipativos, ou seja, não cabe a nenhum sistema aberto que se realiza somente por meio de complexos domínios inter-relacionais. 
Os complexos eventos auto-organizativos só se realizam em sistemas abertos, remetendo-nos às noções de "abertura" e "fechamento" no domínio da organização ativa, como destaca Morin (op.cit),

... as organizações ativas dos sistemas ditos abertos asseguram as trocas, as transformações que alimentam e operam a sua própria sobrevivência: a abertura lhes permite se re-formar sem para; eles se re-formam se fechando, por circuitos múltiplos, retroações negativas, ciclos recursivos ininterruptos [...] Assim, se impõe o paradoxo: um sistema aberto é aberto para se fechar outra vez, mas é fechado para se abrir e se fecha novamente se abrindo. 0 fechamento de um 'sistema aberto' é o fechamento em si. (MORIN, op. cit., p.170)

Na perspectiva organizacional recursiva/ativa a abertura alimenta o sistema e o fechamento mantém sua fronteira operacional (CARACRISTI, 2007): autonomia operacional (fechamento) com dependência ecológica (abertura).

\footnotetext{
A abertura expõe o sistema à entropia geral, que faz o sistema evoluir e se degradar, e o fechamento opera a neguentropia, que se espirala no sistema, fazendo-o renovar-se: o sistema é aberto na medida em que é fechado; o fechamento organizacional, não é o mesmo fechamento da Física clássica. Na concepção clássica, fechar significa interditar, isolar, excluir suas dimensões espaciotemporais. (CARACRISTI, op.cit., p. 106)
}

Como acontece com o evento da "Transformação do Padeiro", todo sistema organizado operacionaliza um fechamento que se processa pela recursão: um processo de iteração que produz repetidas operações de se estender (entropia geral) e se dobrar sobre si mesmo (neguentropia), mantendo os limites de atividade do sistema (sua fronteira operacional).

O padrão espaço-temporal do sistema é mantido pela recursividade circular da organização ativa: a abertura cria a possibilidade de existência do sistema e o fechamento a sua especificação existencial, ou seja, a abertura produz a generalidade de todo sistema aberto e o fechamento a singularidade de cada sistema.

Essas reflexões podem ser reforçadas pelo pensamento de Morin (ib.) quando ele afirma que,

O circuito espiral do redemoinho é na verdade o circuito que se refecha ao se abrir e, por isso, se forma e se reforma ... é por ser aberto - alimentado - que ele é produtor, é por ele se fechar que ele existe como produtor. ... (MORIN, Ib., p.260) 
Assim, a abertura [do sistema] produz a existência; o circuito generativo/recursivo [o fechamento] produz o ser [do sistema].

Ser, existência, si, são emergências de uma totalidade retroagindo recursivamente sobre si mesma enquanto totalidade; são, ao mesmo tempo, produtos-produtores da produção-de-si. (MORIN, Ib., p.261)

Como já afirmamos (CARACRISTI, ib.), o nosso postulado teórico é o de que o clima é produzido pela abertura sistêmica. O que reveste de natureza geográfica a concepção de sistema climático, pois na perspectiva da Climatologia Geográfica é a interação com as paisagens, regiões, territórios e lugares ou na composição geossistêmica que o clima alça sua assinatura geográfica, diferindo-se da perspectiva da Física/Meteorologia.

Seguindo a mesma linha postular, colocamos que a especificação de um determinado tipo climático é produzida pelo seu fechamento recursivo, que singulariza o seu padrão de organização.

A “Constelação Generativa” (Fig. 5) apresentada por Morin em sua brilhante obra "O Método I: A Natureza da Natureza" (2003. p. 263) expõe a Gestalt que traduz a infraestrutura da poiésis climática.

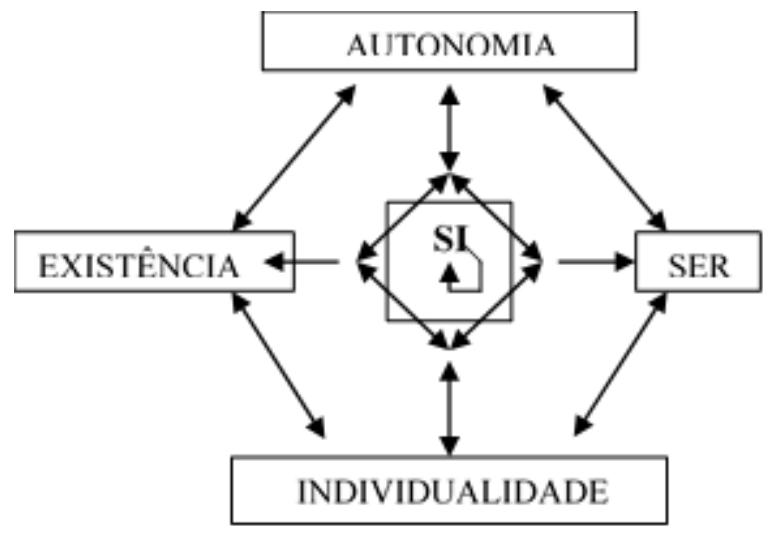

Figura. 5 Constelação Generativa (circuito recursivo, abertura/fechamento, poiésis.) Fonte: Morin (2003) Definir o clima como a "série dos estados da atmosfera em sua sucessão habitual" (SORRE, 1984), determinando-o "pela sucessão habitual dos estados da atmosfera" é uma via de especificação, visto que os parâmetros não-atmosféricos, compõem também o padrão de organização de um clima. 
A referencial proposta metodológica de Monteiro (op.cit) da “Análise Rítmica dos Tipos de Tempo" se apoia na perspectiva sorreana e a associa aos pressupostos teóricos do pensamento sistêmico e complexo, mas lança uma lacuna ao não integrar ao conceito as conexões espaciotemporais que transcendem ao domínio atmosférico. Afinal, o clima, na perspectiva geográfica, contém e está contido na paisagem como um todo, é um padrão de interconexões, um evento emergente do desdobramento dos domínios de relações físicas, químicas e biológicas, os quais denominamos de "elementos e fatores" e que, pela abstração científica, especificamos em nossos procedimentos de análises disciplinares.

A atividade organizativa ou o padrão de organização espaço-temporal (CARACRISTI, ib.) é a chave teórica para avançarmos epistemológica e metodologicamente em nossos estudos geográfico-climáticos,

\begin{abstract}
A estrutura climática ou incorporação física da organização de um sistema climático - que se revela através da paisagem - em qualquer ponto do seu desenvolvimento, é um registro de suas mudanças estruturais anteriores (mudanças em seus elementos constitutivos), e cada mudança estrutural influencia o comportamento futuro do sistema. Isto implica que o comportamento do sistema climático é determinado pelo seu padrão de organização, pela sua estrutura e pelas suas inter-relações com o meio. 0 padrão de organização determina a identidade do sistema (suas características essenciais); a estrutura - formada por uma seqüência de mudanças estruturais, associadas ao acoplamento com o meio - determina o comportamento do sistema. (CARACRISTI, 2007, p. 113).
\end{abstract}

E essa tese se pontencializa quando consideramos também os estados da atmosfera como padrões que emergem sucessivamente, conservando os tipos de tempo por estarem submetidos a domínios relacionais semelhantes. A própria sazonalidade é um padrão de comportamento atmosférico especificado pela teia de inter-relações regionais/zonais/globais que faz emergir o clima envolvente: redes de padrões emergentes que se aninham (Fig. 6) e se processam pela iteração sob determinada intensidade rítmica/dinâmica estrutural da referida teia de relações holônicas.

Figura 5: Curitiba-PR: Painel tempôro-espacial da precipitação pluvial no episódio de 22 de fevereiro de 2016. Elaboração: Mendonça e Buffon (2018). 


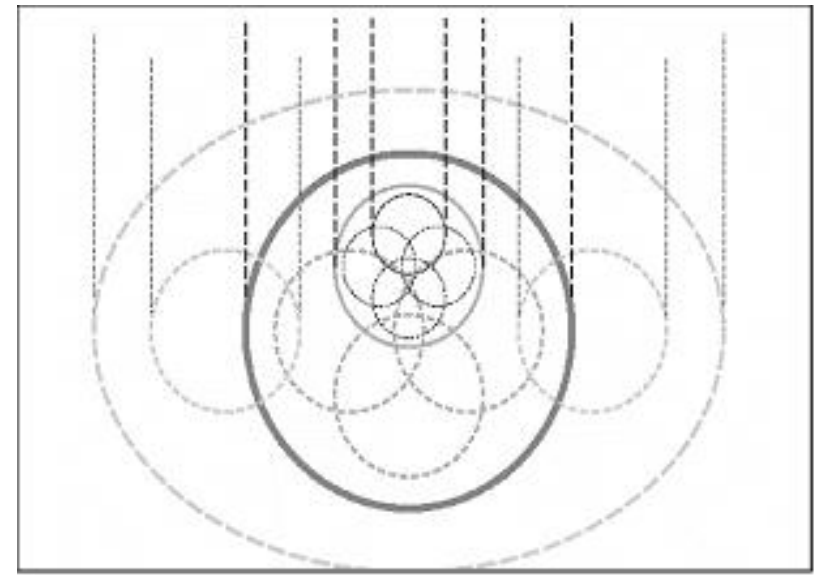

Figura. 6 Rede Holônica: estrutura dinâmica, aninhada e entrelaçadaFonte: Caracristi, 2007.

Os sistemas climáticos integram essa complexa teia de padrões organizativos que se aninham e se entrelaçam e emergem uns nos/pelos outros, conservando-se e sucedendo-se em diversas intensidades e amplitudes.

Cada nódulo da rede é uma parte/todo ou hólons, constituindo padrões ou domínios relacionais. No caso geográfico do clima, o menor domínio de relações fundamentais à dinâmica de organização do sistema se constitui pelo tipo de tempo.

\section{De Monteiro a Maturana, para concluir provocando a reflexão}

Apreciamos a via filosófica em que a Natureza é um ser sempre sendo no devir a ser como apresentada pela Dialética (POLITZER, s/d) ou em que ela se constitui em um "Domínio implicado das frequências holísticas auto-organizadoras" como anunciado nos Paradigmas Holográfico (BOHM e PRIBAM, in WILBER, 2003) e Bootstrap (CHEW, apud Capra, in WILBER, 2003).

Nesse âmbito filosófico e teórico a Natureza torna-se uma matriz processual e não uma síntese (uma coisa, uma substância preconcebida). Ela se revela uma força ativa auto-organizadora, que está subjacente a todo e qualquer padrão que emerge em nossas circunstâncias de observação, incluindo os padrões climáticos. Circunstâncias essas, científicas e históricas, produzem diferentes conceitos de Natureza e de suas apreensões analíticas tais os conceitos atmosfera, clima, relevo, solo entre outros. 
A Natureza, enquanto sistema matriz, existe independente de nossa existência, porém a apreensão de sua existência depende do observador. Se compararmos a espécie humana com outra espécie animal, as apreensões da natureza serão diferenciadas, constituindo seus mundos de percepções (razões biológicas), assim como ocorre entre seres humanos de culturas diversas (razões culturais).

Nunca saberemos como de fato a Natureza é realmente, pois somos da/na Natureza: a Natureza é ao mesmo tempo "em si" e uma construção cognitiva e o clima possui essa mesma ontologia dialeticamente dual. Fato que nos remete a Monteiro (1991) quando ele lança a reflexão "se o clima é um fato ou uma teoria”.

Para MATURANA (2000) não existe mundo sem observador. Equivocadamente podemos deduzir que não existe, então, uma natureza primeira e anterior a nós e que a Natureza é uma "invenção humana", uma teoria humana.

A nosso ver, existe uma diferença teórica/epistemológica entre os conceitos de "Natureza" e de "Mundo".

Defendemos que a natureza não-biológica foi a condição elementar para o surgimento dos domínios criados pelas espécies de micro-organismos unicelulares: a vida originou-se na Terra através da formação e interação de componentes pré-biológicos como os aminoácidos, nucleoproteínas e açucares produzidos não biologicamente (LYNN MARGULIS, in THOMPSON, 2000). Com essa congruência (interação) recursiva dos domínios não-orgânico/pré-biológico e orgânico/biológico primitivos se formou uma natureza original que pode ser considerada um sistema matriz, a partir do qual foram gerados os domínios mais complexos dos reinos vegetais e animais, ou seja, aquela natureza inicial é o sistema matriz que originalmente possibilitou a geração das redes de relações desenvolvidas nos mais diversos domínios biológicos (vegetais e animais) e que, ao mesmo tempo, recursivamente passou a se realizar por meio da interação dinâmica de todos os domínios participantes, em íntimo acoplamento estrutural. 
O conceito de Natureza só se valida em escala integral, enquanto sistema matriz complexo e dinâmico como proposto na Teoria Gaia (LOVELOCK, 1991), configurando-se como sistema universo, o Cosmos, gerando e sendo gerado pelos diversos subsistemas que só se configuram ou se expressam em níveis específicos de análise. Tais subsistemas são os nódulos da imensa teia holônica que é a natureza. São os conectores da complexa estrutura do sistema matriz natural.

Já o mundo, ele é uma dimensão da Natureza gerada pelo processo cognitivo do ser vivo em congruência com seu meio de existência. É o domínio de existência do ser vivo, é uma construção do viver. "... todo ato de conhecer faz surgir um mundo". (Maturana, op.cit, p. 31)

O mundo da espécie humana é fruto da interação dinâmica e recursiva de domínios antecedentes à sua existência com domínios gerados em seu viver: a noção de mundo se dá no processo de viver. Nós construímos o mundo e ele nos constrói, pois somos recursivamente influenciados pelo que criamos e acreditamos existir. “... todo fazer é um conhecer e todo conhecer é um fazer.” (Maturana, ib., p. 32).

Todas as construções cognitivas que compõem o mundo, configuram-se como subsistemas que só se expressam no processo de análise do observador. Desta forma, o conceito de mundo só se valida no nível específico do viver como proposto pela “Teoria da Árvore do Conhecimento" de Maturana (2000).

O que chamamos de "realidade" é o nosso mundo. E as realidades das sociedades humanas são as mais complexas, onde a relação entre sujeito e objeto se constitui na práxis do viver e essa práxis do viver humano se constitui na linguagem, a qual depende da congruência entre as bases biológicas do ser humano e o universo sociocultural desenvolvido no ato de viver de cada sociedade.

Sendo a "realidade" (e todo produto cognitivo como os sistemas naturais) uma construção e não um fato absoluto e independente, isso nos impõe uma responsabilidade ética diante do mundo em que vivemos. 
Daí a fundamental importância de refletirmos nossas epistemes e avançarmos teóricometodologicamente, pois precisamos contribuir com a construção de novas bases de conhecimento do mundo que vivemos, pois a

A reflexão é um processo de conhecer como conhecemos, um ato de voltar a nós mesmos, a única oportunidade que temos de descobrir nossas cegueiras e reconhecer que as certezas e os conhecimentos dos outros são, respectivamente, tão aflitos e tão tênues quanto os nossos. (MATURANA, ib. p. 29)

Façamos como o grande mestre Carlos Augusto Monteiro, que em toda a sua obra foi "mensageiroportador" de inquietas e instigantes reflexões e proposições de cunho teórico, epistemológico e metodológico.

Esclareço que tomo aqui o significado de "mensageiro" como aquele que anuncia. Anunciador ou pressagiador de algo novo, de transcendente valor, ligando, assim, a semântica de mensagem aquela da essência da obra de um geógrafo (cientista, filósofo ou artista) que configure contribuição original por ele trazida à Geografia (Cultura Humana). E "portadores" seriam aqueles ligados à semântica latina do verbo "portare", que designa ao mesmo tempo a dinâmica inicial de "portar" - carregar consigo, levar, conduzir - ao estático final do substantivo "porto": chagar ao porto, fundear, aportar. Aqui o binômio "mensageiro-portador" é uma redução e alta simplificação no complexo processo de transmissão do conhecimento. (MONTEIRO, 1995, p. 14)

Concluímos parafraseando a nós mesmos (CARACRISTI, 2003, p. 23): a Geografia Física pode se tornar um elo indispensável nessa complexa teia do conhecimento interdisciplinar sobre sistemas naturais, compondo uma nova racionalidade ambiental que se instaura no processo científico de compreensão do mundo. Mais do que nunca ousar epistemologicamente se torna uma necessidade da produção geográfica estudos da natureza.

\section{REFERêNCIAS}

CAPRA, Fritjof. A Teia da Vida: Uma nova compreensão científica dos sistemas vivos - Trad. de Newton R. Eichemberg; 9ª ed., São Paulo: Cultrix, 2000.

CARACRISTI, I. Geografia e representações gráficas: uma breve abordagem crítica e os novos desafios técnicometodológicos perpassando pela climatologia, Rio de Janeiro, Revista Brasileira de Cartografia No 55/02, (15 - 24$), 2003$. 
. A natureza complexa da poiésis climática: contribuições teóricas ao estudo geográfico do clima, São Paulo, Tese de Doutorado, Departamento de Geografia Física, FFLCH/USP, 2007.

LOVELOCK, James. As Eras de Gaia: a Biografia da nossa Terra Viva - Trad. de Beatriz Sidou; Rio de Janeiro: Campus, 1991.

MATURANA, Humberto R. e VARELA, Francisco. A Árvore do Conhecimento: as bases biológicas da compreensão humana - São Paulo: Ed. Palas Athenas, 2000.

MONTEIRO, Carlos Augusto de F. A Frente Polar Atlântica e as Chuvas de Inverno na Fachada Sul-Oriental do Brasil Oriental (Contribuição Metodológica à Análise Rítmica dos Tipos de Tempo no Brasil), São Paulo, Tese de Doutoramento, Série Teses e Monografias $n^{0}$ 1, IGEOUSP, 1969.

. Análise Rítmica em Climatologia, São Paulo, Climatologia nº 1, IGEOUSP, 1971.

o Físico da Geografia: Mensageiros e Portadores, Fortaleza: AGB/FUNCEME/UVA,

1995.

Clima e Excepcionalismo: conjecturas sobre o desempenho da atmosfera como fenômeno geográfico, Florianópolis, UFSC, 1991.

. De Tempos e Ritmos: entre o Cronológico e o Meteorológico para a Compreensão Geográfica dos Climas, Rio Claro, Geografia, vol. 26(3), 2001, p. 132 - 154.

MORIN, Edgar. 0 Método I: A Natureza da Natureza - Trad. Ilana Heinberg, $2^{\text {a }}$ Ed., Porto Alegre, Sulina, 2003. POLITZER, G et al. Princípios Fundamentais de Filosofia, Trad. de João C. Andrade; São Paulo: Hemus Editora Ltda., $\mathrm{s} / \mathrm{d}$.

SORRE, M.. Geografia, Tradução de Megale, Januário F., São Paulo, Col. Grandes Cientistas Sociais, nº 46, Ed. Ativa, 1984 .

THOMPSON, W. Irwin (org). Gaia, uma Teoria do Conhecimento, Trad. de Sílvio C. Leite; $2^{\text {a }}$ ed., São Paulo, Gaia Ltda, 2000.

VAN WYLEN, G.J.; SONNTAG, R.E.; BORGNAKKE, C. Fundamentos da termodinâmica. 5. ed. São Paulo: Edgard Blucher Ltda., 1998. 537p

WILBER, Ken (org.) - O Paradigma Holográfico e Outros Paradoxos: Explorando o Flanco Dianteiro da Ciência - Trad. Maria de L. E. e Newton R. E., São Paulo: Cultrix, 4ª Ed., 2003. 